\title{
Effect of Statin Therapy on Fibrous Cap Thickness in Coronary Plaque on Optical Coherence Tomography
}

\author{
- Review and Meta-Analysis -
}

\author{
Yuichi Ozaki, MD, PhD; Hector M. Garcia-Garcia, MD, PhD; Solomon S. Beyene, MD; \\ Alexandre Hideo-Kajita, MD; Kayode O. Kuku, MD; Paul Kolm, PhD; Ron Waksman, MD
}

Background: Statin therapy has been shown to result in coronary plaque regression, but the relationship between statin use and stabilization of coronary plaque has not been elucidated. We conducted a systematic review and meta-analysis to evaluate the effect of statin therapy on fibrous cap thickness (FCT) on optical coherence tomography (OCT).

Methods and Results: Nine OCT studies (6 randomized controlled trials and 3 observational studies) were enrolled with a total of 341 patients (390 lesions). Arms of the studies were grouped according to statin type and/or dose. Random effects meta-analysis was used to estimate a pooled mean change in FCT from baseline to follow-up. The overall effect mean FCT change was $67.7 \mu \mathrm{m}$ (95\% Cl: $\left.51.4-84.1, \mathrm{I}^{2}=95.0 \%, \mathrm{P}<0.001\right)$. All statin groups had an increase in FCT, but the magnitude of the increase differed according to the statin. Two homogeneous subgroups with $\mathrm{I}^{2}=0$ were identified: mean FCT change was $27.8 \mu \mathrm{m}$ (for subgroup atorvastatin $5 \mathrm{mg}$ and rosuvastatin), and $61.9 \mu \mathrm{m}$ (for subgroup atorvastatin $20 \mathrm{mg}$, fluvastatin $30 \mathrm{mg}$, and pitavastatin $4 \mathrm{mg}$ ). On meta-regression modeling, statin therapy alone explained most of the change in FCT.

Conclusions: Statin therapy induced a significant increase in FCT as assessed on OCT, independent of coronary risk factors and other medications.

Key Words: Fibrous cap thickness; Meta-analysis; Optical coherence tomography; Statin

C oronary plaque with lipid-rich pool covered with thin fibrous cap is referred to as high-risk plaque for rupture. ${ }^{1}$ Thin-cap fibroatheroma (TCFA) is recognized as a precursor lesion for plaque rupture.,3 To our knowledge, plaque rupture occurs frequently at the thinnest fibrous cap site and results in acute coronary syndrome (ACS). The fibrous cap usually can be ruptured when it is $<160 \mu \mathrm{m}$ thick and is easier to be ruptured as the fibrous cap thickness (FCT) becomes thinner. ${ }^{4}$ Intravascular optical coherence tomography (OCT) is an intracoronary imaging modality with a high resolution and enables in vivo visualization of the microstructural characteristics of coronary plaque. ${ }^{5}$

Intensive statin therapy results in the reduction of cardiovascular events and suppresses the progression of atherosclerotic plaques. ${ }^{6,7}$ Further, statin therapy also leads to an increase in FCT on OCT, as shown in several clinical trials. ${ }^{7-10}$ This increase of FCT has a significant correlation with decrease of low-density lipoprotein cholesterol (LDLC), ${ }^{9,10}$ but no correlation was observed in another study. ${ }^{8}$
Taken together, the results were not consistent across studies, and most of those studies were small in terms of sample size.

Therefore, we performed a systematic review and metaanalysis to evaluate the effect of statin therapy on FCT using OCT, and the relationship between FCT and coronary risk factors and medication.

\section{Search Strategy}

We conducted a literature search of MEDLINE/PubMed and Web of Science up to July 2018. The search terms were "optical coherence tomography", "fibrous cap", "coronary artery disease", and "statin(s) therapy". Data were abstracted independently by 2 investigators (Y.O. and S.S.B.) in accordance with Preferred Reporting Items for Systematic Reviews and Meta-Analyses (PRISMA) guidelines. ${ }^{11}$

Received December 25, 2018; revised manuscript received March 20, 2019; accepted April 5, 2019; J-STAGE Advance Publication released online May 22, 2019 Time for primary review: 62 days

Section of Interventional Cardiology, MedStar Washington Hospital Center, Washington, DC (Y.O., H.M.G.-G., A.H.-K., P.K., R.W.); MedStar Cardiovascular Research Network, MedStar Washington Hospital Center, Washington, DC (S.S.B., K.O.K.), USA

Mailing address: Hector M. Garcia-Garcia, MD, PhD, Section of Interventional Cardiology, MedStar Washington Hospital Center, 110 Irving Street NW, Suite 4B-1, Washington, DC 20010, USA. E-mail: hector.m.garciagarcia@medstar.net

ISSN-1346-9843 All rights are reserved to the Japanese Circulation Society. For permissions, please e-mail: cj@j-circ.or.jp 
Potentially relevant studies $(n=113)$
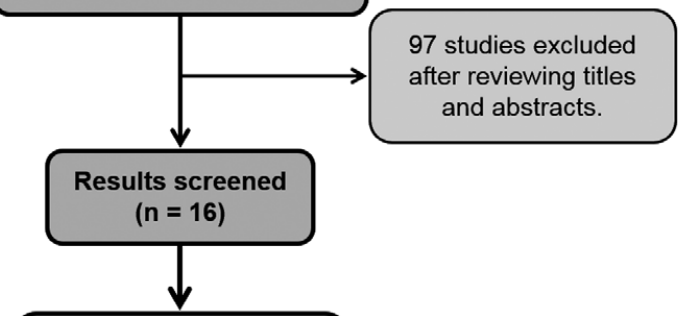

Full-text articles assessed for eligibility ( $n=16)$

Meta-analysis for

"effect of stain therapy on FCT" (15 arms, 341 patients)

eligible studies:

6 RCT + 3 non-RCT
Excluded: $(n=7)$

- No statin therapy (1)

- Other drugs (1)

- No follow-up or baseline data (5)

Figure 1. Flow diagram of the meta-analysis. FCT, fibrous cap thickness; RCT, randomized controlled trial.

\begin{tabular}{|c|c|c|c|c|c|c|c|c|}
\hline \multirow[b]{2}{*}{ Study } & \multirow[b]{2}{*}{ Year } & \multirow[b]{2}{*}{ Study design } & \multirow{2}{*}{$\begin{array}{l}\text { Follow-up } \\
\text { (months) }\end{array}$} & \multirow[b]{2}{*}{ Study drug } & \multirow{2}{*}{$\begin{array}{l}\text { Statin-dose } \\
\text { (mg/day) }\end{array}$} & \multirow{2}{*}{$\begin{array}{c}\text { Clinical } \\
\text { presentation }\end{array}$} & \multicolumn{2}{|c|}{ Study arms } \\
\hline & & & & & & & $\begin{array}{l}\text { Patient } \\
\text { (n) }\end{array}$ & $\begin{array}{l}\text { Lesion } \\
\text { (n) }\end{array}$ \\
\hline Takarada et al ${ }^{7}$ & 2009 & $\begin{array}{c}\text { Non-randomized } \\
\text { (statin vs. non-statin) }\end{array}$ & 9 & $\begin{array}{l}\text { Statin } \\
\text { Non-statin }\end{array}$ & $\begin{array}{l}\mathrm{NR} \\
-\end{array}$ & AMI & $\begin{array}{l}23 \\
17\end{array}$ & $\begin{array}{l}23 \\
17\end{array}$ \\
\hline Imanishi et al ${ }^{8}$ & 2010 & $\begin{array}{l}\text { Non-randomized } \\
\text { (statin vs. non-statin) }\end{array}$ & 9 & $\begin{array}{l}\text { Statin } \\
\text { Non-statin }\end{array}$ & $\begin{array}{l}\text { NR } \\
-\end{array}$ & UAP & $\begin{array}{l}25 \\
15\end{array}$ & $\begin{array}{l}25 \\
15\end{array}$ \\
\hline Hattori et al ${ }^{10}$ & 2012 & $\begin{array}{l}\text { Non-randomized } \\
\text { (pitavastatin vs. diet therapy) }\end{array}$ & 9 & $\begin{array}{l}\text { Pitavastatin } \\
\text { Diet therapy }\end{array}$ & $\begin{array}{l}4 \\
-\end{array}$ & SAP & $\begin{array}{l}26 \\
16\end{array}$ & $\begin{array}{l}26 \\
16\end{array}$ \\
\hline Nishiguchi et al16 & 2018 & RCT (early vs. late) & 9 & Pitavastatin & $\begin{array}{l}4 \text { (early) } \\
4 \text { (late) }\end{array}$ & ACS & $\begin{array}{l}25 \\
28\end{array}$ & $\begin{array}{l}25 \\
28\end{array}$ \\
\hline Nishio et al12 & 2014 & $\begin{array}{l}\mathrm{RCT} \text { (rosuvastatin vs. } \\
\text { rosuvastatin+EPA) }\end{array}$ & 9 & $\begin{array}{c}\text { Rosuvastatin } \\
\text { Rosuvastatin+EPA }\end{array}$ & $\begin{array}{l}3.50 \pm 3.25 \\
3.67 \pm 2.08\end{array}$ & ACS+SAP & $\begin{array}{l}15 \\
15\end{array}$ & $\begin{array}{l}26 \\
23\end{array}$ \\
\hline Habara et $\mathrm{al}^{\mathbf{1 3}}$ & 2014 & $\begin{array}{l}\text { RCT (fluvastatin vs. } \\
\text { fluvastatin+ezetimib) }\end{array}$ & 9 & $\begin{array}{c}\text { Fluvastatin } \\
\text { Fluvastatin+ezetimib }\end{array}$ & $\begin{array}{l}30 \\
30\end{array}$ & SAP & $\begin{array}{l}26 \\
31\end{array}$ & $\begin{array}{l}26 \\
31\end{array}$ \\
\hline Komukai et al9 & 2014 & $\begin{array}{l}\text { RCT (atorvastatin } \\
5 \mathrm{mg} \text { vs. } 20 \mathrm{mg} \text { ) }\end{array}$ & 12 & Atorvastatin & $\begin{array}{r}5 \\
20\end{array}$ & UAP & $\begin{array}{l}30 \\
30\end{array}$ & $\begin{array}{l}30 \\
30\end{array}$ \\
\hline Hou et al ${ }^{14}$ & 2016 & $\begin{array}{l}\text { RCT (atorvastatin } \\
20 \mathrm{mg} \text { vs. } 60 \mathrm{mg} \text { ) }\end{array}$ & 12 & Atorvastatin & $\begin{array}{l}20 \\
60\end{array}$ & CAD & $\begin{array}{l}19 \\
27\end{array}$ & $\begin{array}{l}30 \\
36\end{array}$ \\
\hline Wang et al ${ }^{15}$ & 2016 & $\begin{array}{l}\text { RCT (atorvastatin } \\
20 \mathrm{mg} \text { vs. } 60 \mathrm{mg} \text { ) }\end{array}$ & 12 & Atorvastatin & $\begin{array}{l}20 \\
60\end{array}$ & CAD & $\begin{array}{r}9 \\
12\end{array}$ & $\begin{array}{l}16 \\
15\end{array}$ \\
\hline
\end{tabular}

Data given as mean \pm SD or $\mathrm{n}$. ACS, acute coronary syndrome; $\mathrm{AMI}$, acute myocardial infarction; CAD, coronary artery disease; EPA, eicosapentaenoic acid; NR, not reported; RCT, randomized control trial; SAP, stable angina pectoris; UAP, unstable angina pectoris.

\section{Selection Criteria}

The inclusion criteria were as follows: (1) trials providing coronary FCT assessed using OCT at baseline and followup (6-12 months); (2) trials with $>1$ group of patients receiving statin therapy; (3) clinical studies published in peer-reviewed journals; and (4) reports in English. The exclusion criteria were: (1) trials analyzing in-stent morphology; and (2) reviews, meeting abstracts, or unpublished literature. 


\begin{tabular}{|c|c|c|c|c|c|c|}
\hline Study & Study arm & $\begin{array}{c}\text { Age } \\
\text { (years) }\end{array}$ & Male & DM & HTN & DLP \\
\hline Takarada et al ${ }^{7}$ & Statin & $62 \pm 10$ & $14(61)$ & $7(30)$ & $14(61)$ & $23(100)$ \\
\hline Imanishi et $\mathrm{a}^{8}$ & Statin & $66 \pm 11$ & $17(68)$ & $13(52)$ & $16(64)$ & $20(80)$ \\
\hline Hattori et al10 & Pitavastatin & $66 \pm 7.8$ & $25(96.1)$ & $9(34.6)$ & $13(50)$ & NR \\
\hline \multirow[t]{2}{*}{ Nishiguchi et al ${ }^{16}$} & Early pitavastatin & $66(63-71)$ & $19(76)$ & $10(40)$ & $15(60)$ & $25(100)$ \\
\hline & Late pitavastatin & $66(62-74)$ & $23(82)$ & $9(32)$ & $19(68)$ & $28(100)$ \\
\hline \multirow[t]{2}{*}{ Nishio et $a^{12}$} & Rosuvastatin & $63.8 \pm 9.5$ & $13(86.7)$ & $2(13.3)$ & $10(66.7)$ & NR \\
\hline & Rosuvastatin+EPA & $61.0 \pm 12.6$ & $13(86.7)$ & 5 (33.3) & $11(73.3)$ & NR \\
\hline \multirow[t]{2}{*}{ Habara et al'13 } & Fluvastatin & $68.8 \pm 7.8$ & $26(83)$ & $13(41)$ & $18(58)$ & NR \\
\hline & Fluvastatin+ezetimib & $69.8 \pm 7.8$ & $21(65)$ & $11(34)$ & $23(71)$ & NR \\
\hline \multirow[t]{2}{*}{ Komukai et al9 } & Atorvastatin $5 \mathrm{mg}$ & $69(58-74)$ & $22(73)$ & $6(20)$ & $20(67)$ & $30(100)$ \\
\hline & Atorvastatin $20 \mathrm{mg}$ & $63(58-73)$ & $26(87)$ & 7 (23) & $18(60)$ & $30(100)$ \\
\hline \multirow[t]{2}{*}{ Hou et $\mathrm{al}^{14}$} & Atorvastatin $20 \mathrm{mg}$ & $54 \pm 9.3$ & $13(68)$ & $9(47)$ & $12(63)$ & NR \\
\hline & Atorvastatin $60 \mathrm{mg}$ & $55 \pm 10$ & $17(63)$ & $11(41)$ & $15(56)$ & NR \\
\hline \multirow[t]{2}{*}{ Wang et al15 } & Atorvastatin $20 \mathrm{mg}$ & $55.1 \pm 6.8$ & $5(55.6)$ & $5(55.6)$ & 7 (77.8) & $1(11.1)$ \\
\hline & Atorvastatin $60 \mathrm{mg}$ & $60.3 \pm 6.7$ & $5(41.7)$ & $3(25)$ & $9(75)$ & $4(33.3)$ \\
\hline
\end{tabular}

\begin{tabular}{|c|c|c|c|c|c|c|c|c|}
\hline \multirow{2}{*}{ Smoker ${ }^{\dagger}$} & \multirow{2}{*}{ Previous MI } & \multicolumn{3}{|c|}{ Target vessel } & \multicolumn{4}{|c|}{ Medication } \\
\hline & & LAD & LCX & RCA & ACEI/ARB & $\beta$-blocker & CСВ & Nitrates \\
\hline $10(43)$ & $3(13)^{\ddagger}$ & $N R$ & $\mathrm{NR}$ & $N R$ & $16(70)$ & $12(52)$ & $\mathrm{NR}$ & $5(22)$ \\
\hline $10(40)$ & NR & $14(56)$ & $4(16)$ & 7 (28) & $18(72)$ & $7(28)$ & NR & NR \\
\hline $14(53.8)$ & NR & $15(57.7)$ & 0 & $11(42.3)$ & $18(69)$ & $12(46)$ & $9(35)$ & NR \\
\hline $10(40)$ & NR & $10(40)$ & $8(32)$ & $7(28)$ & $7(28)$ & $3(12)$ & $8(32)$ & NR \\
\hline $10(36)$ & NR & $11(39)$ & $7(25)$ & $10(36)$ & $7(25)$ & $1(4)$ & $7(25)$ & NR \\
\hline $9(60)$ & NR & NR & NR & NR & $9(60)$ & $3(20)$ & 5 (33.3) & NR \\
\hline $12(80)$ & NR & NR & NR & NR & $10(66.7)$ & $3(20)$ & $2(13.3)$ & NR \\
\hline $10(32)$ & NR & $10(32)$ & $8(26)$ & $13(42)$ & $17(54.8)$ & $2(7)$ & $14(45)$ & $6(19)$ \\
\hline $7(21)$ & NR & $9(28)$ & $15(47)$ & $8(25)$ & $10(31.3)$ & $2(6)$ & $14(43)$ & $6(19)$ \\
\hline $15(50)$ & NR & $10(33)$ & $6(20)$ & $14(47)$ & $27(90)$ & $18(60)$ & $3(10)$ & NR \\
\hline $19(63)$ & NR & $14(47)$ & $8(27)$ & $8(27)$ & $26(87)$ & $20(67)$ & $4(13)$ & NR \\
\hline $8(42)$ & $4(21)$ & $8(27)$ & $6(20)$ & $16(53)$ & $7(37)$ & $11(58)$ & $4(21)$ & $11(58)$ \\
\hline $15(56)$ & $7(26)$ & $12(33)$ & $7(20)$ & $17(47)$ & $13(48)$ & $19(70)$ & $8(30)$ & $15(56)$ \\
\hline $4(44.4)$ & 3 (33.3) & $4(25)$ & $3(18.8)$ & 9 (56.3) & $6(66.7)$ & $6(66.7)$ & $2(22.2)$ & 5 (55.6) \\
\hline $5(41.7)$ & $2(16.7)$ & 5 (33.3) & $4(26.7)$ & $6(40)$ & $5(41.7)$ & $9(75)$ & $5(41.7)$ & $6(50)$ \\
\hline
\end{tabular}

${ }^{+}$Current or previous. ${ }^{\prime}$ Previous coronary artery disease. Data given as mean $\pm S D$, median (IQR), or $n(\%)$. ACEI, angiotensin-converting enzyme inhibitor; ARB, angiotensin-II receptor blocker; CCB, calcium channel blocker; DLP, dyslipidemia; DM, diabetes mellitus; EPA, eicosapentaenoic acid; HTN, hypertension; LAD, left anterior descending; LCX, left circumflex; MI, myocardial infarction; NR, not reported; RCA, right coronary artery.

\section{Data Extraction and Quality Assessment}

Two reviewers (Y.O. and S.S.B.) independently evaluated the studies for eligibility and extracted the data. The following variables were entered into a dedicated extraction form: study design, patient characteristics, type and dose of statins, follow-up duration, coronary risk factors, and OCT findings including FCT and lipid arc. Inconsistencies in the extraction of the data were resolved in a consensus meeting looking at the original reports.

The primary endpoint was the change in FCT between baseline and follow-up after statin therapy. FCT was defined as the minimum thickness of the signal-rich band overlying the lipid core, as previously described in the consensus document. 5 The second outcome was the change in lipid arc after statin therapy.

\section{Statistical Analysis}

Random effects meta-analysis was used to assess study heterogeneity and estimate a pooled mean change in FCT from baseline to follow-up. Because the data are paired (change from baseline to follow-up), meta-analysis calculations for comparing 2 independent treatment groups do not apply. The correlation between baseline and follow-up measures for each study is needed to calculate the proper standard error of differences. This is likely not provided in published studies: patient-level data would be needed. Based on patient-level data obtained from 2 of the studies (The EASY-FIT Study and The ESCORT Study), the correlation between baseline and follow-up FCT was 0.70 . This was the correlation used to calculate the standard error for paired differences. It is, of course, possible that the correlation would not be the same from study to study. As sensitivity analyses, the standard error was recalculated 


\begin{tabular}{|c|c|c|c|c|c|c|c|c|c|}
\hline \multirow{2}{*}{ Study } & \multirow{2}{*}{ Study arm } & \multicolumn{2}{|c|}{ TC (mg/dL) } & \multicolumn{2}{|c|}{ LDL-C (mg/dL) } & \multicolumn{2}{|c|}{ HDL-C (mg/dL) } & \multicolumn{2}{|c|}{ Triglycerides (mg/dL) } \\
\hline & & Baseline & Follow-up & Baseline & Follow-up & Baseline & Follow-up & Baseline & Follow-up \\
\hline Takarada et al ${ }^{7}$ & Statin & $218 \pm 16$ & $166 \pm 22$ & $144 \pm 22$ & $91 \pm 12$ & $41 \pm 8$ & $45 \pm 6$ & $158 \pm 50$ & $142 \pm 38$ \\
\hline Imanishi et a| ${ }^{8}$ & Statin & $207 \pm 47$ & $164 \pm 34$ & $129 \pm 40$ & $85 \pm 25$ & $44 \pm 10$ & $49 \pm 17$ & NR & NR \\
\hline Hattori et al10 & Pitavastatin & $197 \pm 46$ & $164 \pm 24$ & $134 \pm 40$ & $89 \pm 23$ & $46 \pm 11$ & $58 \pm 16$ & $147 \pm 48$ & $137 \pm 82$ \\
\hline \multirow[t]{2}{*}{ Nishiguchi et al ${ }^{16}$} & Early pitavastatin & $\begin{array}{c}185 \\
(171-199)\end{array}$ & $\begin{array}{c}140 \\
(123-149)\end{array}$ & $\begin{array}{c}117 \\
(105-129)\end{array}$ & $\begin{array}{c}67 \\
(63-78)\end{array}$ & $\begin{array}{c}40 \\
(38-45)\end{array}$ & $\begin{array}{c}41 \\
(37-48)\end{array}$ & $\begin{array}{c}103 \\
(80-156)\end{array}$ & $\begin{array}{c}116 \\
(92-146)\end{array}$ \\
\hline & Late pitavastatin & $\begin{array}{c}190 \\
(177-213)\end{array}$ & $\begin{array}{c}143 \\
(124-167)\end{array}$ & $\begin{array}{c}118 \\
(109-135)\end{array}$ & $\begin{array}{c}76 \\
(56-91)\end{array}$ & $\begin{array}{c}43 \\
(37-49)\end{array}$ & $\begin{array}{c}45 \\
(38-54)\end{array}$ & $\begin{array}{c}95 \\
(84-144)\end{array}$ & $\begin{array}{c}100 \\
(81-128)\end{array}$ \\
\hline \multirow[t]{2}{*}{ Nishio et al'12 } & Rosuvastatin & $196.3 \pm 40.3$ & $146.3 \pm 20.5$ & $130.3 \pm 34.8$ & $83.2 \pm 19.6$ & $41.5 \pm 7.4$ & $43.6 \pm 9.4$ & $146.8 \pm 37.4$ & $131.4 \pm 47.9$ \\
\hline & Rosuvastatin+EPA & $207.3 \pm 39.1$ & $144.4 \pm 36.5$ & $138.0 \pm 35.3$ & $80.1 \pm 29.7$ & $40.9 \pm 12.0$ & $44.9 \pm 9.9$ & $161.4 \pm 50.4$ & $123.5 \pm 42.6$ \\
\hline \multirow[t]{2}{*}{ Habara et al13 } & Fluvastatin & $193.8 \pm 37.4$ & $177.5 \pm 37.2$ & $109.1 \pm 30.2$ & $100.8 \pm 27.6$ & $48.1 \pm 10.2$ & $49.1 \pm 11.1$ & $113 \pm 60.6$ & $118 \pm 27.6$ \\
\hline & Fluvastatin+ezetimib & $197.8 \pm 37.4$ & $160.4 \pm 35.4$ & $122.5 \pm 33.6$ & $88.5 \pm 29.5$ & $49.9 \pm 13.0$ & $50.6 \pm 12.2$ & $126 \pm 50.4$ & $142 \pm 81.3$ \\
\hline \multirow[t]{2}{*}{ Komukai et al9 } & Atorvastatin $5 \mathrm{mg}$ & $\begin{array}{c}195 \\
(176-216)\end{array}$ & $\begin{array}{c}159 \\
(130-195)\end{array}$ & $\begin{array}{c}117 \\
(110-138)\end{array}$ & $\begin{array}{c}78 \\
(66-108)\end{array}$ & $\begin{array}{c}42 \\
(34-53)\end{array}$ & $\begin{array}{c}43 \\
(35-54)\end{array}$ & $\begin{array}{c}138 \\
(85-169)\end{array}$ & $\begin{array}{c}128 \\
(96-154)\end{array}$ \\
\hline & Atorvastatin $20 \mathrm{mg}$ & $\begin{array}{c}194 \\
(176-220)\end{array}$ & $\begin{array}{c}143 \\
(128-156)\end{array}$ & $\begin{array}{c}127 \\
(111-155)\end{array}$ & $\begin{array}{c}69 \\
(61-80)\end{array}$ & $\begin{array}{c}43 \\
(34-49)\end{array}$ & $\begin{array}{c}45 \\
(36-49)\end{array}$ & $\begin{array}{c}109 \\
(86-176)\end{array}$ & $\begin{array}{c}96 \\
(78-132)\end{array}$ \\
\hline \multirow[t]{2}{*}{ Hou et al ${ }^{14}$} & Atorvastatin $20 \mathrm{mg}$ & NR & NR & $115 \pm 28$ & $80 \pm 32$ & $50 \pm 12$ & $50 \pm 18$ & NR & NR \\
\hline & Atorvastatin $60 \mathrm{mg}$ & NR & NR & $114 \pm 23$ & $67 \pm 21$ & $47 \pm 10$ & $41 \pm 8.3$ & NR & NR \\
\hline \multirow[t]{2}{*}{ Wang et al15 } & Atorvastatin $20 \mathrm{mg}$ & $215 \pm 42$ & $164.9 \pm 51.7$ & $121.2 \pm 26.9$ & $93 \pm 35.3$ & $52.6 \pm 14.1$ & $46.9 \pm 19.4$ & NR & NR \\
\hline & Atorvastatin $60 \mathrm{mg}$ & $198.2 \pm 32.6$ & $139.2 \pm 24$ & $110.3 \pm 25.4$ & $69.3 \pm 16.6$ & $49.8 \pm 10.8$ & $43.1 \pm 14.2$ & NR & NR \\
\hline
\end{tabular}

Data given as mean \pm SD or median (IQR). EPA, eicosapentaenoic acid; HDL-C, high-density lipoprotein cholesterol; LDL-C, low-density lipoprotein cholesterol; NR, not reported; TC, total cholesterol.

assuming correlations of 0.2 and 0.5 . Given the means and standard deviations of baseline and follow-up data, the standard deviation of baseline to follow-up differences is:

$\mathrm{SD}($ baseline- follow-up $)=$

$\sqrt{\text { variance(baseline)+variance(follow-up)-2*r*(SD(baseline)*(SD(follow-up)) }}$

where $r$ is the correlation of the paired differences. The standard error of paired differences is then given by dividing the standard deviation by the square root of the sample size. Thus, the data for the meta-analysis was study mean difference with its estimated standard error. The same issue applies when performing meta-regression of change in lipid levels with change in FCT from baseline to follow-up. Using patient data from the EASY-FIT and ESCORT study, the standard error of the regression was estimated from the total cholesterol (TC), LDL-C, and high-density lipoprotein cholesterol (HDL-C) regressions with the change in FCT.

Arms of the studies were grouped according to similar statins and/or doses (Supplementary Table). Random effects meta-analysis was used to obtain a pooled estimate of change in FCT/lipid arc of the statin groups and assess statin group heterogeneity using the $\mathrm{I}^{2}$ statistic. If $\mathrm{I}^{2}$ was large, studies were identified with $\mathrm{I}^{2}<10 \%$ and pooled estimates of change were made.

Linear regression was used to assess the association of statin use with change in FCT and lipid arc (weighting the regression with the number of patients in each arm). Data provided by the studies that could be used in multivariable analysis included age, sex, diabetes, hypertension, smoking, angiotensin-converting enzyme inhibitor/angiotensinII receptor blocker (ACEI/ARB), and $\beta$-blocker use. For each model, the $\mathrm{R}^{2}$ statistics (and $\mathrm{P}$-value) are provided. Because some of the statin arms were from the same study, "Study" was included in the regression analyses as a random effect. Stata v15 (Stata Corp, College Station, TX,
USA) was used for all analyses.

\section{Results}

A total of 113 reports were identified in the search. After excluding duplication and screening the titles and abstracts, 16 studies were retrieved for full-text reviews. Of these 16 studies, 7 were excluded, and 9 studies ( 6 randomized controlled trials $[\mathrm{RCT}]$ and 3 non-randomized placebo controlled studies) met the inclusion criteria. To evaluate the effect of statin therapy on FCT, we included 15 arms in these 9 OCT studies: 13 arms receiving only statin treatment (6 used atorvastatin, 3 pitavastatin, 1 rosuvastatin, 1 fluvastatin, and 2 others a mix of them) and 2 arms receiving combination treatment (rosuvastatin+eicosapentaenoic acid and fluvastatin+ezetimib), in which there was a total of 341 patients with 390 target lesions, in the meta-analysis (Figure 1). Of note, all patients were Asian, and, as such, statin dose was given accordingly. The target lesions in all of the studies were non-culprit lesions.

Table 1 summarizes the characteristics of the included studies. Six studies were RCT,,12-16 and the other 3 studies were non-randomized placebo controlled studies. ${ }^{7,8,10}$ Table 2 lists the baseline patient characteristics of all patients. Patient age range was 54-69 years old, and $41-96 \%$ of patients were male. The length of the follow-up period was 12 months in the 3 studies $9,14,15$ and 9 months in the other 6 studies. ${ }^{7,8,10,12,13,16}$ In the 3 studies including the EASY-FIT study, 2 different dosages of atorvastatin were used.9,14,15 Two studies compared statin and other lipidlowering agents (eicosapentaenoic acid and ezetimib) in addition to statin, 12,13 and the other 3 studies compared with statin and without statin., ${ }^{7,810}$ The ESCORT study investigated the effect of the timing of statin ( 3 or 36 weeks) in patients with ACS. ${ }^{16}$ Lipid arc data were provided in 5 of the studies.9,12-14,16 The lipid profiles in the included studies are described in Table 3. 
A

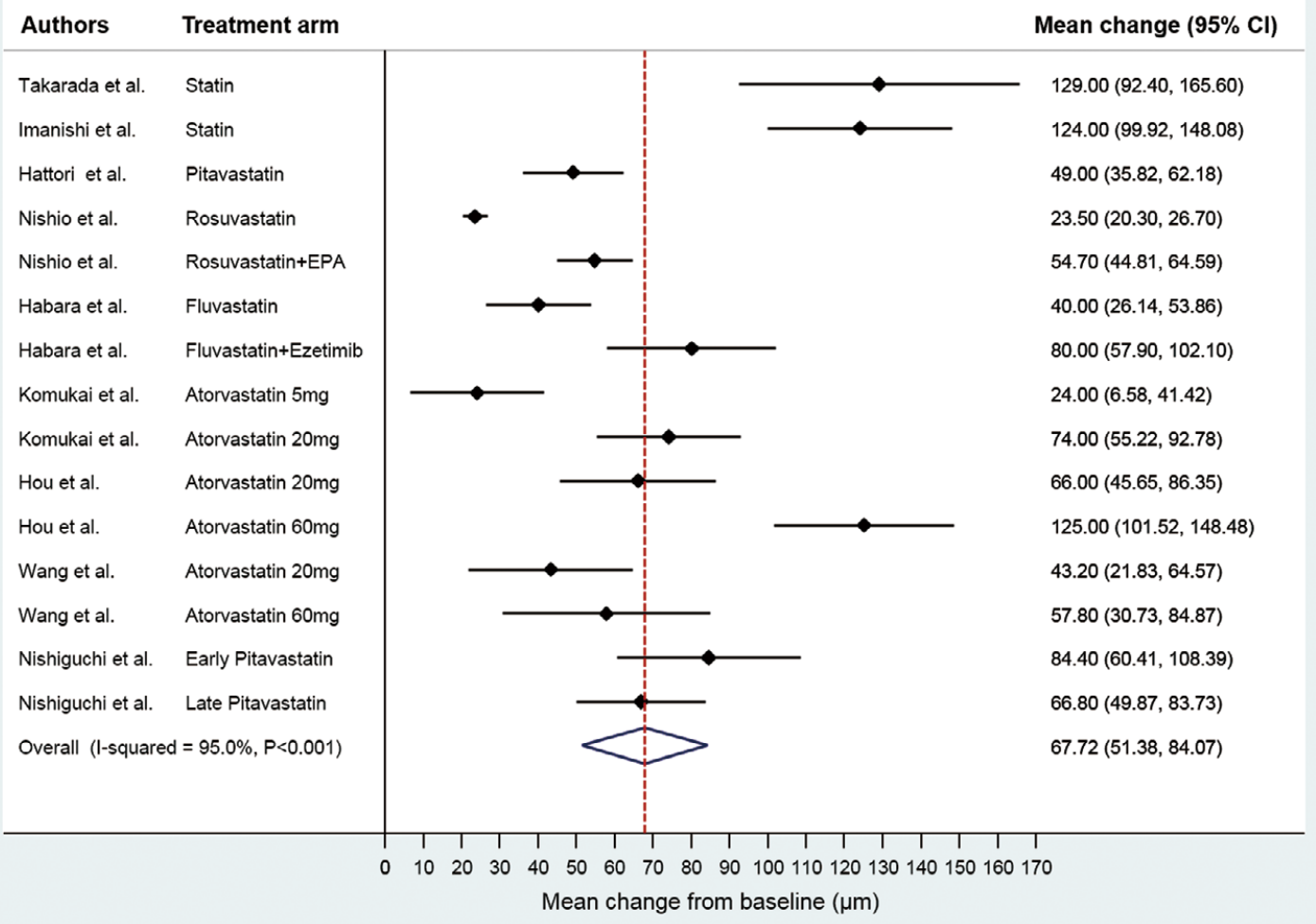

B

Statin

\begin{tabular}{l} 
Atorvastatin $5 \mathrm{mg}$ \\
Rosuvastatin \\
\hline
\end{tabular}

\begin{tabular}{l} 
Atorvastatin $20 \mathrm{mg}$ \\
Fluvastatin $30 \mathrm{mg}$ \\
Pitavastatin $4 \mathrm{mg}$ \\
\hline
\end{tabular}

Atorvastatin $60 \mathrm{mg}$

Statin

\section{Mean change $(95 \% \mathrm{Cl})$}

$24.00(7.64,40.36)$

$38.15(11.18,65.11)$

$58.91(43.23,74.59)$

$61.75(34.81,88.70)$

$66.40(47.28,85.52)$

$96.10(80.22,111.98)$

$126.50(107.29,145.70)$

Figure 2. Forest plots of (A) overall studies, comparing change in fibrous cap thickness (FCT) from baseline to follow-up, and (B) the 2 homogenous subgroups identified with $I^{2}=0$, comparing change in FCT for 2 groups. Positive value indicates increase. EPA, eicosapentaenoic acid. 
A

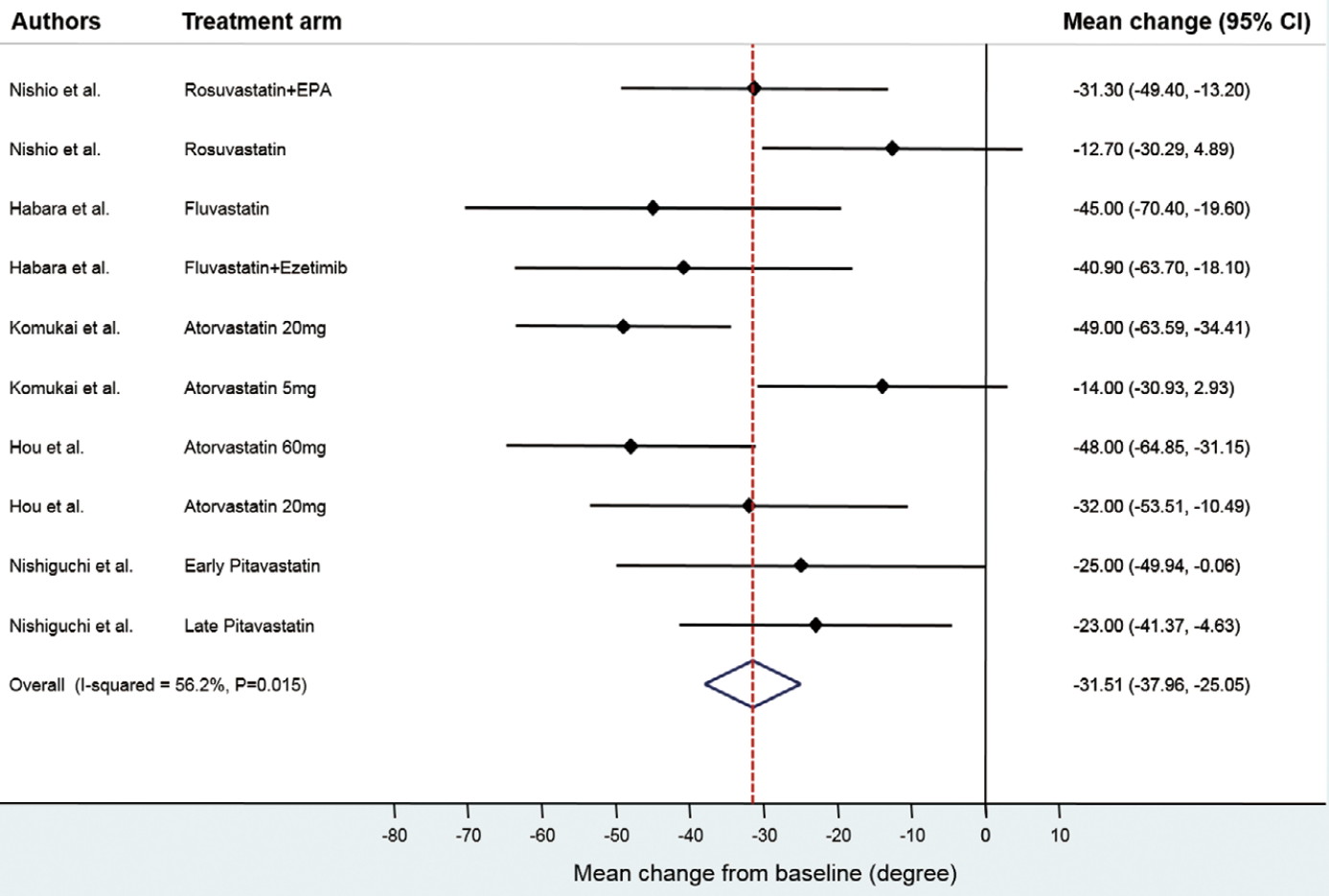

B

Statin

Mean change $(95 \% \mathrm{Cl})$

Atorvastatin $60 \mathrm{mg}$

Atorvastatin $20 \mathrm{mg}$

Atorvastatin $5 \mathrm{mg}$

Pitavastatin $4 \mathrm{mg}$

Fluvastatin 30mg

Rosuvastatin

Overall (I-squared $=0.0 \%, P=0.505)$

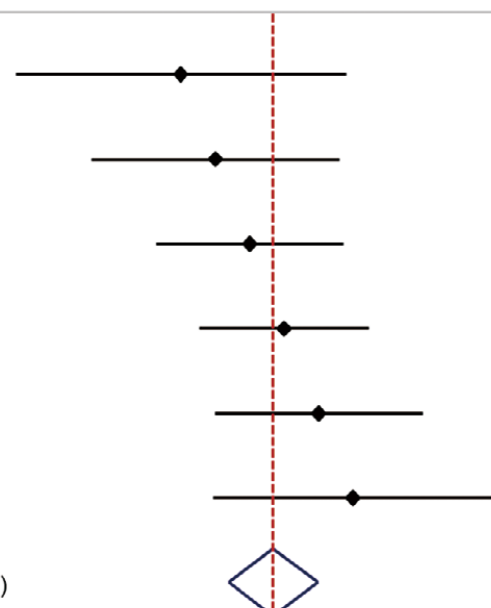

$-40.40(-54.65,-26.15)$

$-37.43(-48.16,-26.71)$

$-34.46(-42.54,-26.39)$

$-31.50(-38.82,-24.17)$

$-28.53(-37.50,-19.56)$

$-25.56(-37.63,-13.49)$

$-32.44(-36.31,-28.58)$

Figure 3. Forest plot of $(\mathbf{A})$ the studies including lipid arc, and $(\mathbf{B})$ the statin groups with $\mathrm{I}^{2}=0$, comparing changes in lipid arc from baseline to follow-up. Negative value indicates decrease. EPA, eicosapentaenoic acid. 
The overall ungrouped random effect mean FCT change was $67.7 \mu \mathrm{m}\left(95 \%\right.$ CI: 51.4-84.1, $\mathrm{I}^{2}=95.0 \%, \mathrm{P}<0.001$; Figure 2A). Pooling of the 9 studies, however, resulted in considerable heterogeneity (between-study variability $\left[\mathrm{I}^{2}\right]$ was $95.0 \%$ ). Meta-analysis of the statin groups identified 2 homogenous subgroups with $\mathrm{I}^{2}=0$ for both: atorvastatin $5 \mathrm{mg}$ and rosuvastatin (mean FCT change, $27.8 \mu \mathrm{m} ; 95 \%$ CI: $13.8-41.8$ ) and atorvastatin $20 \mathrm{mg}$, fluvastatin $30 \mathrm{mg}$, and pitavastatin $4 \mathrm{mg}(61.9 \mu \mathrm{m}, 95 \% \mathrm{CI}$ : $50.8-72.9)$. The atorvastatin $60 \mathrm{mg}$ and statin groups stood alone with larger mean increases in FCT than any of the other groups and differed from each other as well (Figure 2B). Although all statin groups had an increase in FCT, the estimate of the change varied from $27 \mu \mathrm{m}$ to $>100 \mu \mathrm{m}$.

On pooling of the 5 RCT with valid lipid arc data (consisting of a total of 246 patients), the random effect mean lipid arc change from baseline to follow-up was $-31.5^{\circ}$ (95\% CI: -38.0 to $-25.1, \mathrm{I}^{2}=56.2 \%, \mathrm{P}=0.015$, Figure 3A). On meta-analysis of the statin groups, the mean change in lipid arc was $-32.4^{\circ}(95 \% \mathrm{CI}:-36.3$ to -28.6$)$ with $\mathrm{I}^{2}=0$ (Figure 3B).

Statin group accounted for $75.6 \%$ of the change in FCT from baseline to follow-up. The covariates that accounted for $>10 \%$ of the variance were age for $11.1 \%$, male gender for $18.9 \%$, diabetes mellitus for $20.7 \%$, and ACEI/ARB for $11.2 \%$ (Table 4A). Furthermore, when included with the statin group, only a trivial change in $\mathrm{R}^{2}$ was observed

Table 4. Percent of Variance Accounted for in FCT Change

\begin{tabular}{lrr}
\multicolumn{1}{c}{ Model } & $\mathbf{R}^{\mathbf{2}}(\%)$ & P-value \\
(A) Univariate models & & \\
Statin group & 75.6 & $<0.001$ \\
Age & 11.1 & 0.082 \\
Male & 18.9 & 0.144 \\
Diabetes & 20.7 & 0.018 \\
Hypertension & 5.0 & 0.459 \\
Smoker & 3.8 & 0.280 \\
ACEl/ARB & 11.2 & 0.020 \\
$\beta$-blocker & 1.3 & 0.629 \\
(B) 2-factor multivariable models & & \\
Statin group+ & 75.6 & $<0.001$ \\
Age & 76.5 & $<0.001$ \\
Male & 75.8 & $<0.001$ \\
Diabetes & 75.9 & $<0.001$ \\
Hypertension & 76.0 & $<0.001$ \\
Smoker & 76.8 & $<0.001$ \\
ACEl/ARB & 77.5 & $<0.001$ \\
$\beta$-blocker & 78.2 & $<0.001$ \\
\hline
\end{tabular}

ACEI, angiotensin-converting enzyme inhibitor; ARB, angiotensin-II receptor blocker; FCT, fibrous cap thickness.
(Table 4B). In lipid arc change, the statin group accounted for $90 \%$ of the change (data not shown). Meta-regression analysis of the change in FCT with the changes in lipid profile after statin therapy is given in Table 5. Significant correlations were observed between the change in FCT and the changes in TC $(\mathrm{P}=0.025)$ and LDL-C $(\mathrm{P}=0.012)$, but not in HDL-C $(\mathrm{P}=0.427)$ during follow-up.

The risk of bias in all included studies is shown in Supplementary Figure. Most of the studies were judged as having a low risk of bias (reported in green). Six of the 9 studies were randomized,,912-16 and 3 of the nine studies used random sequence generation., $9,13,16$ All of the randomized studies reported details of dropouts or withdrawals and of the inclusion and exclusion criteria.

\section{Discussion}

The present meta-analysis reports on the changes in FCT in 6 RCT and 3 non-randomized placebo controlled studies in patients with coronary artery disease (CAD) treated with statin therapy: first, the pooled mean increase from the 9 studies would not be a valid and reliable estimate of the effect of statin on change in FCT because the pooling resulted in considerable heterogeneity (between-study variability $\left[\mathrm{I}^{2}\right]$ was $>90 \%$ ). There were, however, statistically significantly different estimates of mean FCT change ( $27.8 \mu \mathrm{m}$ for subgroup: atorvastatin $5 \mathrm{mg}$ and rosuvastatin; and $61.9 \mu \mathrm{m}$ for subgroup: atorvastatin $20 \mathrm{mg}$, fluvastatin $30 \mathrm{mg}$, and pitavastatin $4 \mathrm{mg}$ ) based on the identification of 2 homogeneous subgroups with $\mathrm{I}^{2}=0$. And second, on multivariate modeling, statin therapy was most associated with change in FCT. To the best of our knowledge, this is the first meta-analysis to evaluate the impact of statin therapy on FCT in coronary plaque using OCT, based on combining studies considered as homogeneous.

The FCT is considered a crucial determinant of plaque vulnerability: 1 of the main characteristics of high-risk coronary plaque is the thinning of the fibrous cap. Nowadays, OCT is regarded as the only intracoronary imaging modality that can detect FCT in vivo, due to its high spatial resolution. ${ }^{3}$ So far, several OCT studies have demonstrated that FCT in coronary plaque could increase with statin therapy. ${ }^{7-10,12-16}$ Most of these OCT studies on the effect of statin on plaque morphology including FCT, however, had small sample sizes and different treatment effects; therefore, we conducted the present meta-analysis to obtain more confirmatory evidence. After pooling the results, we found an increase of $67.7 \mu \mathrm{m}$ in FCT with statin therapy. Pooling of the 9 studies, however, resulted in considerable heterogeneity $\left(\mathrm{I}^{2}=95.0 \%, \mathrm{P}<0.001\right)$. Zhen et al reported that statin therapy induced a significant increase of $59 \mu \mathrm{m}$ in FCT on OCT $\left(\mathrm{I}^{2}=87.3 \%, \mathrm{P}<0.001\right)$. The observed heterogeneity in this latter report makes it non-interpretable. ${ }^{17}$ In other words, large heterogeneity

\begin{tabular}{|ccccc|}
\hline \multicolumn{4}{c}{ Table 5. Change in FCT With Change in Lipids After Statin Therapy: Meta-Regression Analysis } \\
Variable & Regression coefficient & SE & t-value & P-value \\
Change in TC & -2.263 & 0.646 & -3.50 & 0.025 \\
Change in LDL-C & -2.251 & 0.581 & -3.88 & 0.012 \\
Change in HDL-C & -5.120 & 5.928 & -0.86 & 0.427 \\
\hline
\end{tabular}

FCT, fibrous cap thickness; HDL-C, high-density lipoprotein cholesterol; LDL-C, low-density lipoprotein cholesterol; TC, total cholesterol. 
means that the studies are non-"poolable". We, therefore, investigated the combination of studies for which $\mathrm{I}^{2}=0$, and fibrous cap thickening was observed in each group with homogeneity. A thin fibrous cap overlying a large lipid core, especially with FCT $<65 \mu \mathrm{m}$, known as TCFA, is regarded as the precursor lesion for plaque rupture and induces ACS. Tanaka et al reported that plaque with FCT $<160 \mu \mathrm{m}$ was at risk for plaque disruption and that it could be easier to rupture as the FCT becomes thinner. ${ }^{4}$ Although statin therapy has been recognized to reduce cardiovascular events and mortality in patients with CAD ${ }^{18,19}$ the detailed mechanism remains to be fully elucidated. Previous intravascular ultrasound studies have demonstrated that statin therapy may result in plaque stabilization by regressing plaque volume and modifying plaque composition. ${ }^{\mathbf{2 0 , 2 1}}$ The present meta-analysis has also shown that statin therapy significantly decreases lipid arc. Plaque stabilization, by fibrous cap thickening and reduction of the lipid component, is a probable mechanism in statin therapy.

Coronary risk factors have been shown to predict cardiovascular events. ${ }^{22}$ The current study, however, did not confirm a significant relationship between the increase of FCT and age, male gender, and coronary risk factors including diabetes, hypertension, and smoking, beyond statin therapy. Additionally, previous OCT showed that there were no significant differences in FCT between men and women, ${ }^{23}$ or between diabetes and non-diabetes. ${ }^{24} \mathrm{~A}$ previous meta-analysis that assessed the effect of statin on FCT also similarly reported that an increase in FCT was not associated with coronary risk factors. ${ }^{17}$ These findings are consistent with the present report. In contrast to the previous meta-analysis, however, we found a significant relationship between changes in TC and LDL-C and the change in FCT. This was most likely due to the correct analysis of paired data, given that paired analyses are more powerful than analyses of independent groups.

Taken together, the present study suggests that statin therapy induced fibrous cap thickening (i.e., plaque stabilization) as evidenced by the increased FCT on OCT. There were, however, large and statistically significantly different estimates of the treatment effect (change of FCT from baseline to follow-up) based on combining studies for which differences in treatment effect were due to random sampling variability (i.e., $\mathrm{I}^{2}=0$ ). A potential explanation for this is the dose of statin and statin type. This needs to be further investigated in comparative randomized studies.

\section{Study Limitations}

The present study has some limitations. First, in this metaanalysis, we combined the data derived from different studies with different types of statins, follow-up periods, concomitant medication, and clinical presentations (stable angina or ACS). Second, all included studies were from Asian medical centers; strictly all of them were in Japan and China. Thus, there might be a potential selection bias, and hence the external validity is limited. The IBIS 4 study (conducted solely in European countries) has been recently published showing an increase in FCT in patients with STsegment elevation myocardial infarction taking high-dose rosuvastastin. ${ }^{25}$ We did not include this in the present report, in order to not increase heterogeneity further. Finally, 3 of the included studies were non-randomized trials.

\section{Conclusions}

Statin therapy, more than any other cardiovascular risk factor and medication, induced significant change (i.e., increase) in coronary FCT as assessed on OCT.

\section{Disclosures}

Y.O.: grant support, Sumitomo Life Welfare and Culture Foundation. R.W.: advisory boards of Abbott Vascular, Amgen, Boston Scientific, Medtronic, Philips Volcano, Pi-Cardia, Cardioset; consultant, Abbott Vascular, Amgen, Biosensors, Biotronik, Boston Scientific, Medtronic, Philips Volcano, Pi-Cardia, Cardioset; grant support, Abbott Vascular, AstraZeneca, Biosensors, Biotronik, Boston Scientific, Chiesi; speakers bureau, AstraZeneca, Chiesi; investor, MedAlliance. The other authors declare no conflicts of interest.

\section{References}

1. Virmani R, Burke AP, Farb A, Kolodgie FD. Pathology of the vulnerable plaque. J Am Coll Cardiol 2006; 47: C13-C18.

2. Brezinski ME, Tearney GJ, Bouma BE, Izatt JA, Hee MR, Swanson EA, et al. Optical coherence tomography for optical biopsy: Properties and demonstration of vascular pathology. Circulation 1996; 93: 1206-1213.

3. Virmani R, Kolodgie FD, Burke AP, Farb A, Schwartz SM. Lessons from sudden coronary death: A comprehensive morphological classification scheme for atherosclerotic lesions. Arterioscler Thromb Vasc Biol 2000; 20: 1262-1275.

4. Tanaka A, Imanishi T, Kitabata H, Kubo T, Takarada S, Tanimoto T, et al. Morphology of exertion-triggered plaque rupture in patients with acute coronary syndrome: An optical coherence tomography study. Circulation 2008; 118: 2368-2373.

5. Tearney GJ, Regar E, Akasaka T, Adriaenssens T, Barlis P, Bezerra HG, et al. Consensus standards for acquisition, measurement, and reporting of intravascular optical coherence tomography studies: A report from the International Working Group for Intravascular Optical Coherence Tomography Standardization and Validation. J Am Coll Cardiol 2012; 59: 1058-1072.

6. Dohi T, Miyauchi K, Okazaki S, Yokoyama T, Yanagisawa N, Tamura $\mathrm{H}$, et al. Early intensive statin treatment for six months improves long-term clinical outcomes in patients with acute coronary syndrome (Extended-ESTABLISH trial): A follow-up study. Atherosclerosis 2010; 210: 497-502.

7. Takarada S, Imanishi T, Kubo T, Tanimoto T, Kitabata $\mathrm{H}$, Nakamura N, et al. Effect of statin therapy on coronary fibrouscap thickness in patients with acute coronary syndrome: Assessment by optical coherence tomography study. Atherosclerosis 2009; 202: 491-497.

8. Imanishi $\mathrm{T}$, Ikejima $\mathrm{H}$, Tsujioka $\mathrm{H}$, Kuroi $\mathrm{A}$, Ishibashi $\mathrm{K}$, Komukai K, et al. Association of monocyte subset counts with coronary fibrous cap thickness in patients with unstable angina pectoris. Atherosclerosis 2010; 212: 628-635.

9. Komukai K, Kubo T, Kitabata H, Matsuo Y, Ozaki Y, Takarada S, et al. Effect of atorvastatin therapy on fibrous cap thickness in coronary atherosclerotic plaque as assessed by optical coherence tomography. J Am Coll Cardiol 2014; 64: $2207-2217$

10. Hattori K, Ozaki Y, Ismail TF, Okumura M, Naruse H, Kan S, et al. Impact of statin therapy on plaque characteristics as assessed by serial OCT, grayscale and integrated backscatterIVUS. JACC Cardiovasc Imaging 2012; 5: 169-177.

11. Moher D, Liberati A, Tetzlaff J, Altman D. Preferred reporting items for systemic reviews and meta-analyses: The PRISMA statement. PLoS Med 2009; 6: e1000097.

12. Nishio R, Shinke T, Otake H, Nakagawa M, Nagoshi R, Inoue $\mathrm{T}$, et al. Stabilizing effect of combined eicosapentaenoic acid and statin therapy on coronary thin-cap fibroatheroma. Atherosclerosis 2014; 234: 114-119.

13. Habara M, Nasu K, Terashima M, Ko E, Yokota D, Ito T, et al. Impact on optical coherence tomographic coronary findings of fluvastatin alone versus fluvastatin+ezetimibe. Am J Cardiol 2014; 113: $580-587$.

14. Hou J, Xing L, Jia H, Vergallo R, Soeda T, Minami Y, et al. Comparison of intensive versus moderate lipid-lowering therapy on fibrous cap and atheroma volume of coronary lipid-rich plaque using serial optical coherence tomography and intravascular ultrasound imaging. Am J Cardiol 2016; 117: 800-806.

15. Wang Z, Cho YS, Soeda T, Minami Y, Xing L, Jia H, et al. 
Three-dimensional morphological response of lipid-rich coronary plaques to statin therapy: A serial optical coherence tomography study. Coron Artery Dis 2016; 27: 350-356.

16. Nishiguchi T, Kubo T, Tanimoto T, Ino Y, Matsuo Y, Yamano $\mathrm{T}$, et al. Effect of early pitavastatin therapy on coronary fibrouscap thickness assessed by optical coherence tomography in patients with acute coronary syndrome: The ESCORT study. JACC Cardiovasc Imaging 2018; 11: 829-838.

17. Zheng G, Chen J, Lin C, Huang X, Lin J. Effect of statin therapy on fibrous cap thickness in coronary plaques using optical coherence tomography: A systematic review and meta-analysis. J Int Cardiol 2015; 28: 514-522.

18. Sacks FM, Pfeffer MA, Moye LA, Rouleau JL, Rutherford JD, Cole TG, et al. The effect of pravastatin on coronary events after myocardial infarction in patients with average cholesterol levels. N Engl J Med 1996; 335: 1001-1009.

19. Pedersen TR, Kjekshus J, Berg K, Haghfelt T, Faergeman O, Faergeman G, et al. Randomized trial of cholesterol-lowering in 4444 patients with coronary heart disease: The Scandinavian simvastatin survival study (4s). Lancet 1994; 344: 1383 - 1389.

20. Nicholls SJ, Ballantyne CM, Barter PJ, Chapman MJ, Erbel $\mathrm{RM}$, Libby P, et al. Effect of two intensive statin regimens on progression of coronary disease. N Engl J Med 2011; 365: 2078 2087.

21. Nozue T, Yamamoto S, Tohyama S, Umezawa S, Kunishima T, Sato A, et al. Statin treatment for coronary artery plaque com- position based on intravascular ultrasound radiofrequency data analysis. Am Heart J 2012; 163: 191-199.e1.

22. Grundy SM, Pasternak R, Greenland P, Smith S, Fuster V. Assessment of cardiovascular risk by use of multiple-risk-factor assessment equations: A statement for healthcare professionals from the American Heart Association and the American College of Cardiology. Circulation 1999; 100: 1481-1492.

23. Chia S, Raffel OC, Takano M, Tearney GJ, Bouma BE, Jang IK. In-vivo comparison of coronary plaque characteristics using optical coherence tomography in women vs. men with acute coronary syndrome. Coron Artery Dis 2007; 18: 423-427.

24. Yonetsu T, Kato K, Uemura S, Kim BK, Jang Y, Kang SJ, et al. Features of coronary plaque in patients with metabolic syndrome and diabetes mellitus assessed by 3-vessel optical coherence tomography. Circ Cardiovasc Imaging 2013; 6: 665-673.

25. Räber L, Koskinas KC, Yamaji K, Taniwaki M, Roffi M, Holmvang $\mathrm{L}$, et al. Changes in coronary plaque composition in patients with acute myocardial infarction treated with highintensity statin therapy (IBIS-4): A serial optical coherence tomography study. JACC Cardiovasc Imaging, doi:10.1016/j. jcmg.2018.08.024.

\section{Supplementary Files}

Please find supplementary file(s);

http://dx.doi.org/10.1253/circj.CJ-18-1376 